\title{
VEIKKO RANTALA
}

\section{THE LITERARY WORK AND INTENTIONALITY}

\section{CONTROVERSIES}

In recent decades, one of the most controversial and lively issues in the philosophy of art, aesthetics, and literary criticism has been the relevance of the author's intention for the identity and interpretation of a work of art. It has been argued, for instance, that the author's intention cannot and should not contribute to the identity of a literary work or to its acceptable interpretations. According to Wimsatt and Beardsley (1954) and Beardsley (1958), literary works are public objects and their meanings must be found out by relying on public linguistic conventions and rules. Aesthetic and cultural criteria - such as the requirement that a reading should maximize coherence and complexity of the text - can be used when the linguistic conventions admit more than one meaning, since they are internal to the work and they are also public. Somewhat later, Elgin and Goodman (1986) argue against the relevance of intention by saying that a work may not realize the author's intentions, they are private and vague and we may not know them, and the work may symbolize things which are different from what the author intended. To understand the work is not to understand what the author meant by it.

The intentionalist camp defends the view that the author's intention is at least of some importance for identity and it can and should be taken into account in interpretation. On the other hand, there is an interesting controversy among the intentionalists: some of them hold that the author's intention is external to a work, whereas others argue that it is internal, even to such a degree that there is a kind of 'logical' connection between the text, or syntax, of the work and the author's intention. The most influential proponent of the former view is Hirsch (1967) who argues that the author's intention provides a genuinely discriminating norm for interpreting a work. A sophisticated defence of the latter view is provided by Juhl (1980) who maintains that "there is a logical connection between statements about the meaning of a literary work and statements about the author's intention such that a statement about the meaning of a work is a statement about the author's intention" (p.12). 
The intentionalists' arguments are often motivated by the view that a text has or it should be given a unique interpretation - and the correct interpretation is determined by what the author meant by the text. Linguistic rules or textual features do not necessarily yield any unique interpretation. Many anti-intentionalists, such as Wimsatt and Beardsley, seem to think that uniqueness is desirable - even though they have to admit that it may not be possible to achieve by means of internal evidence - whereas some of them are explicitly relativists, as, for instance, Goodman and Elgin who argue that multiplicity of meaning, ambiguity, is a positive and important feature of literary texts.

In fact, so many alternatives have been presented that it is hard to find any new ones. But the arguments are often based on characteristic examples rather than on theoretical investigations. Such examples, both actual examples and thought experiments, are important, of course, since they help us to clarify conceptual issues concerning interpretation, but, on the other hand, the issues should also be considered in sufficiently advanced theoretical frameworks - and, as far as the role of intentionality in literary criticism is concerned, there exist only few such attempts, as for example, some applications of speech act theory. Therefore, I will in this paper consider the matter in the light of some philosophical aspects of cognitive science, in particular, by studying logical features of intentionality, and hope that this would throw some new light onto the matter. The aim of this paper is rather restricted and tentative, however. I will mainly apply the theory to the view defended by Juhl (1980) that the meaning of a literary work logically depends on the author's intention.

\section{INTENTIONALITY}

Since Brentano, it is commonly held - not unanimously, however - that intentionality is a feature that distinguishes mental from physical (Brentano's Thesis). Mental states, or mental acts, are intentional when they are directed at objects or states of affairs. In this sense, intentional states are mental representations of relevant objects and states of affairs. Thus believing, knowing, imagining are intentional states, they are directed at and they represent relevant things. Likewise, intending is intentional if Mary has an intention to write a poem, it is an intentional state which is directed at her writing a poem. Mary may have additional intentions to express or describe, or otherwise symbolize something with the poem, intentions concerning its syntactical structure, and so forth. Intention is just a kind of intentional state, whence 
intentions have similar logical and ontological properties as intentional states in general.

This conception is somewhat confused by such suggestions as that mental is reducible to physical, that machines and plants can have intentionality, that intentionality is a kind of intensionality. I cannot enter in any detailed discussion of different conceptions of intentionality - different interpretations of the notion - nor controversies involved. For the purposes of the present paper, the most important variations of the notion are its weakened or generalized forms which allow us to speak about intentionality even in connection with things which are not mental. This, so to say, builds a bridge between mental states and symbol systems.

Let us consider a couple of well-known generalizations of Brentano's notion. Dennett (1981) defines intentionality as a feature of linguistic entities. An idiom is intentional if substitution of coextensional terms does not preserve truth or if the objects 'referred' to in the idiom are not capturable in the usual way by quantifiers (op.cit. p.3). It seems to me, however, that it is more common to use the word 'intensionality' about such features of linguistic entities - and it will be used in what follows. Furthermore, Dennett says that a system is an intentional system if its behavior can be explained and predicted by ascribing to it beliefs or desires or intensions, etc., that is, if its features can be explained and predicted by adopting an intentional stance toward it. Thus something is an intentional system only in relation to our explanatory and predictive strategies which assign intentional features to it. The system need not really have beliefs or desires or intentions in the same sense as persons have, but one can study it meaningfully by adopting a methodological stance of ascribing them to it. The intentional stance presupposes the assumption that the system has some amount of rationality and that it possesses relevant information. Its behaviour cannot be explained or predicted only in a mechanistic or causal manner - for example, because of its complexity. Dennett argues that one may consider - besides persons - computers, animals and plants as intentional systems in this sense, that is, to take - methodologically - the intentional stance toward them. So, this is a generalization of Brentano's notion and it even applies to physical objects, but it is not, perhaps, the best for my present purposes.

A slightly different generalization is made by Dretske (1981). He argues that the information a signal carries exhibits the same kind of intentionality as belief, knowledge, intending, etc. If a signal carries certain information, it does not necessarily carry an extensionally equivalent piece of information. This is the case, for instance, if the two pieces of information are only accidentally correlated. Dretske (1981, p.76) proposes that there is a 
connection between human and informational intentionality and that the intentionality of our cognitive states can be understood as symptoms of their underlying information-theoretic character. The intentionality of a persons beliefs, intentions, etc., is however, of higher order than that of information in the sense that 'extensional equivalence' can be replaced by 'nomic equivalence', even 'by analytic equivalence' (op. cit. pp. 172-173). An observation made by Dretske - and by many others, of course - which is more relevant for my forthcoming arguments is that when intentional phenomena, such as information, are deseribed, an intensional language must be used. A sentence is intensional, for example, if the replacement of a predicate expression by an extensionally (or nomically or analytically) equivalent predicate expression may alter the truth value of the sentence. I will later study the notion of intensional language in more detail.

Searle (1983) provides a similar generalization of the notion, but it seems to fit better than the other generalizations to what I have in mind. $\mathrm{He}$ makes a distinction between 'intrinsic' and 'derived' intentionality, the former belonging to persons and the latter to some other entities (op.cit. pp 26-28). Beliefs, for instance, are intrinsically intentional. When a person expresses his belief by performing a speech act, that is, uttering a relevant sentence, he by this act imposes intentionality on the physical entity - composed of sounds or written marks - which is the product of the utterance. In this way the utterance derives its intentionality from the intentionality of the corresponding mental state. Since, on the other hand, the speech act is performed with the intention to express the belief in question, this is how the utterance receives its meaning. As Dretske, Searle also says that sentences about intentionality are often intensional. They fail to satisfy certain tests of extensionality, such as substitutivity of identicals and existential generalization.

\section{INTENTIONALITY}

Let us take a sharper look at the question of how intentionality is mirrored in our language, that is, what it means that sentences about intentional systems are intensional. Let us consider statements reporting intentional mental states, say, beliefs. I only take up some features - they are in fact much discussed in epistemology and epistemic logic. The considerations can be generalized for intentional features of literary works, as I hope to point out shortly.

Examples of the following kinds are well-known from the literature of epistemic logic: 


\section{Example 1. It is true that}

The Evening Star is the Morning Star

Yet it seems possible to say that the following sentences are both true:

(2) Mary believes that the Morning Star is a planet;

(3) Mary does not believe that the Evening Star is a planet.

This is an example which violates the following principle of Substitutivity of Identicals:

(ID) If $a=b$, then $C(. . . a . .$.$) and C(. . . b .$.$) are equivalent,$ where $\mathrm{C}(. .$.$) is a relevant linguistic context. This principle is considered as one$ landmark of extensionality.

Example 2. This example is about the intensional feature, mentioned by Dretske, that a replacement of a predicate expression by an equivalent (in some sense) expression may not preserve the truth value. I only consider the strongest case where equivalence means analytic or logical equivalence (in an appropriate sense of 'analytic' or 'logical') since the other cases mentioned above are more obvious. At least on some notion of belief it may happen that the following are both true:

Mary believes that the door is closed;

Mary does not believe that the door is closed and either the window is open or is not open;

despite the fact that the embedded sentences are logically equivalent (in a relevant sense of logical). So, we may: see that even the following general principle, which is one of the weakest landmarks of extensionality, does not hold in general about intentional contexts:

(RE) If $\mathrm{A}$ and $\mathrm{B}$ are equivalent, then $\mathrm{C}(. . . \mathrm{A} . .$.$) and \mathrm{C}(. . . \mathrm{B} . .$. are equivalent.

Example 3. If we regard 'equivalence' of $\mathrm{C}($...A...) and $\mathrm{C}(. . . \mathrm{B} . .$.$) as meaning that$ they entail (in a relevant sense) each other, we see that if (RE) does not hold, then the following principle does not hold either:

(RM) If $A$ entails $B$, then $C(. . . A . .$.$) entails C(. . B . .$.$) ;$

or expressed slightly differently:

If $\mathrm{A}$ entails $\mathrm{B}$ and $\mathrm{C}(. . . \mathrm{A} . .$.$) holds, then \mathrm{C}(. . . \mathrm{B}$...) holds.

In the context of knowledge - that is, if $C(.$.$) is an epistemic context, as, for$ example, 'Mary knows that...'- if the entailment in (RM) means logical consequence, the principle states what is often called 'logical omniscience' since we may then say something like this: Mary knows all the logical consequences of what she knows. This and the other features of extensionality mentioned above go together with idealized notions of belief and knowledge. It is 
sometimes said that if an agent's knowledge and beliefs comply with the extensionality principles, the agent is 'rational'- since the agent's attitudes agree with the underlying logic (which is often taken to be classical). This way of interpreting 'rationality' is, of course, somewhat intricate, and it does not sound acceptable to me, but it is not my aim to discuss it here. Dennet, anyway, seems to intepret it so (see Dennett,1981, pp. 10-12).

\section{INTENTIONALITY AND LITERARY WORKS}

It is argued by Rosenthal (1986) that Searle's theory is not able to make a real distinction between intrinsic and derived intentionality. Furthermore, it is not always clear whether Searle assigns derived intentionality to speech acts only or to their physical realizations - marks and sounds - as well. The latter alternative seems to be the case, however. It is evident that speech acts are intentional as human acts.

Such questions are not the most crucial for my forthcoming arguments, however, so that I shall ignore the criticism. What is more important here is to see that the notions of intrinsic and derived intentionality seem to be applicable in the context of artistic creation as it is in the context of speech acts. A work is a result of its author's intentional acts - which in some sense are analogous to speech acts, or, rather, they are speech acts in a generalized sense (see, e.g., Pratt, 1977; Kjørup, 1978) - whence we may assume that the artist in this way imposes intentionality on the work, or the text or syntax of the work, and hence meaning. At this point of analysis, there is little difference whether one takes the work to be a mere physical or syntactical entity - which I do not do - or something more. If we accept the view that the author puts intentionality - meaning - onto the work, then it is, however, natural to think that it is something more than a syntactical or physical entity. What matters here is that it can be regarded as a symbol (system) having intentionality in the derived sense. It then follows that reports of - i.e., sentences used to discuss - the content of the work, what it symbolizes, are intensional.

That the work derives intentionality from the author very strongly suggests that its meaning is in some sense 'logically' - or 'necessarily'connected with the author's intention, i.e., that the connection can be defended by logical rather than normative or cognitive arguments. It clearly implies, on one hand, that there is a connection, and, on the other hand, that the connection is necessary.

Hence, the notion of derived intentionality seems to support the literary theorists who argue for such a logical connection. For instance, 
according to Cioffi (1978, pp. 317-318), "[t]he notion of the author's intention is logically tied to the interpretation we give to his work". Our language, and first of all, our minds work this way, says Cioffi. "The work will be considered more conclusive evidence of the author's intention that his own statements..." since "... we may feel that he was mistaken as to what his intention was."

Juhl (1980) presents a very elaborated and explicit defence of the view that there is a logical connection between the meaning of a literary work and the author's intention. If a text has at least two possible interpretations under the rules of the language - the author's intention logically determines which of them is correct. Hence, "...to understand a literary work is...to understand what the author intended to convey or express" (op. cit .p.47.) I cannot discuss Juhl's arguments in greater detail here - they are much more involved and sophisticated than one might think on the basis of my simplified account. What I like to do is to point out that the logic of intentionality may cast some doubts onto Juhl's main arguments, even though the notion of derived intentionality seems to support what he argues for - as we saw. The very intentionality of the work implies that the logic needed to discuss its meaning is intensional, as we learnt above so that the context in which arguments about the symbolic properties of the work are embedded is opaquewhence well-known troubles follow affecting some of his arguments.

There are much discussed textual features, such as complexity and coherence, to which one is assumed to appeal in order to make one's choice between possible interpretations. Thus, for instance, if one interpretation makes a work more coherent than another, the former should be chosen. Such criteria are defended, for example, by Beardsley, but Juhl goes farther as he claims that to appeal to complexity or coherence is to appeal to the author's intention: "... a feature of the text ... will constitute evidence for the meaning of a work if and only if it is evidence of what the author intended to convey" (op. cit. pp.47-48). If one interpretation makes the text more coherent than another, it is more likely - though not certain - that the former interpretation corresponds to the author's intention since it explains why the author used the words he used in the text. For Juhl, a given interpretation is an explanation of the author's use of the words which constitute the text. So, assuming coherence and other relevant textual features yields a kind of functional explanation of why the author wrote what he wrote.

Juhl's example of coherence is a much discussed poem by Wordsworth, its following line:

Rolled round in earth's diurnal course.

He claims that it is more likely that the author's intention is to suggest slow and gentle motion than violent motion since this explains why he used the 
words 'in earth's diurnal course' to qualify the expression 'rolled round'. The former interpretation is more coherent than the latter with the line (6). For Beardsley, coherence is just an evidence for a correct interpretation, whereas Juhl considers it as an evidence for the author's intention. If, on the other hand, the line (6) had come into existence by accident - and not by an intentional act coherence would not provide any functional explanation of anything.

This seems acceptable to me, to some extent, but we may ask whether this kind of reasoning can be generalized or whether it is only applicable to such specific examples as the one mentioned. Let us assume, for example, that a text A (or a sentence of a text) entails B in some logical or every-day sense, or that it logically entails $B$ when conjoined with an appropriate 'law', or something like that. To avoid 'paradoxes' of implication, we may even assume that the connection between $A$ and $B$ is also relevant in an appropriate sense. Then we may say that $B$ is coherent with $A$, even more coherent than any sentence which is not relevantly entailed by $A$. Yet - in view of the fact that meaning is assumed to be intentional - it may not even be likely that the author suggested the state of affairs represented (or described) by $B$ rather than something else.

This is a consequence of the fact that the logic of interpretation is intensional - in the same sense as the logic of propositional attitudes which I discussed earlier. In a condensed form, this feature can be described as follows, if we, for simplicity, only consider representation, the question of what a work represents, or rather, what the author represents by the work. Then, for example, analogously to what we said about knowledge and belief, the principle (RM) is not in general applicable to representation. That is, the following is not necessarily the case:

If $A$ entails $B$ and the work (i.e. the author) represents that $A$, then it (the author) represents that $B$.

If we admit that meaning is intentional, so that the logic of representation is intensional, we have to accept this claim and the corresponding claims which can be associated with the other features of extensionality discussed earlier. Therefore, the work need not even represent states of affairs which are 'very coherent' with it as far as what is represented is a matter of the authorial intention, as Juhl assumes. So it looks that such a textual feature as coherence need not be evidence for the author's intentions. This is in fact perfectly compatible with Juhl's arguments; he seems to admit that there are cases in which coherence is not a criterium of what the text means. But it is not obvious what 
they are, in addition to those where texts are produced by chance i.e., cases where intention is not present.

It is somewhat confusing here, however, that Juhl seems to hold the view that all implications of the text are intentional since the text is (op.cit.pp. 128-148). According to him, though the author is not aware of all associations and implications, yet they can be considered as belonging to the range of his intentions: "The claim that ... implications are largely unintended rests on the mistaken assimilation of intending to planning" (op.cit. p. 150). It is true that not all intentional states are conscious, but if we assume that all implications are intended, thus belonging to the intended interpretation, then we are close to assuming that the logic of interpretation is extensional after all. If it is not extensional, questions of the following kind are raised: If $A$ entails both $B$ and $C$ and $B$ is while $C$ is not intended, why is it that accepting $B$ does but accepting $C$ does not provide an explanation of the textual feature $A$ and that the textual feature $\mathrm{A}$ is an evidence for the interpretation conveyed by $\mathrm{B}$ but not for the interpretation conveyed by $\mathrm{C}$ ?

It seems to me that Juhl is assuming that the author is ideally - or rather, almost ideally - rational, perhaps even logically or factually 'omniscient'. Only on such an assumption one may argue that "[a]n interpretation is expected to provide an explanation [referring to some purpose of the author] of the features of the text" (op.cit. p.87). Logical extensionality principles - such as (7), which Juhl seems to hold, as we saw - may perhaps be considered as reflecting one dimension of rationality (cf. section 3, above), though this assumption is a little controversial. When we study the behavior of an 'intentional system', " [w] start by assuming rationality" (Dennett, 1981, p.9). According to Dennett, the presumption of rationality is so strongly entrenched in our inference habits that we do not easily question the rationality of the system as a whole. "The assumption that something is an intentional system is the assumption that it is rational" (op.cit. pp.10-11). One gets nowhere with the assumption that an entity has certain beliefs unless one also supposes that the entity believes what follows from the given beliefs. This is a methodological starting point suggested by Dennett and it has been adopted by Juhl as well, as it seems to me. In the long run, this may usually be a good strategy of interpretation - at least when the author is known as a competent language user - and it justifies arguments pertaining to textual features, as, for example, the argument that it is likely that the more coherent interpretation is the one the author intended.

On the other hand, however, it is an important feature of intentionality in general that it does not always go together with ideal rationality. In particular instances we have to tolerate "less than optimal 
performance" (Dennett, 1981,p.19) Exceptions are characteristic of intentional systems. In view of this feature, one has to raise the question what we should do when we actually interpret a particular text and its particular points. Do we have to conclude that no individual interpretation is more than plausible if it has to be in accordance with the author's intentions? This conclusion is drawn by some scholars as, for instance, Margolis (1980).

What has been said casts serious doubts on the kind of argumentation by which Juhl defends the objectivist idea that there is a logical connection between the meaning of a work and what the author intended. The very notion of intentionality seems to be the obstacle. One may ask, however, whether it is necessary to stick to the intended interpretation in the first place. There are semantic and cognitive reasons to argue that the author's intended interpretation should be considered as contributing to the original identity of the work - irrespective of whether it can be found out (see Haapala, 1988; Rantala, 1990). This is simply because authors do not usually wish to write texts which have no specific meaning over and above their conventional linguistic meanings. On the other hand, however, there seem to be no cognitive, logical, or ethical reasons to require that readers could not search for other interpretations which are in some sense good, correct, or plausible. Rather, an essential aesthetic role of artworks is that they, as artworks, allow different readings, even tentative or strongly theory-relative ones.

\section{REFERENCES}

Beardsley, M.C., Aesthetics: Problems in the Philosophy of Criticism, Harcourt, Brace \& World, New York, 1958.

Dennett, D., Brainstorms, MIT Press, Cambridge, Mass.-London, 1981.

Cioffi, F., 'Intention and Interpretation in Criticism', in J. Margolis (ed.), Philosophy Looks at the Arts, Temple University Press, Philadelphia, 1978.

Dretske, F.I., Knowled ge and the Flow of Information, Blackwell, Oxford, 1981.

Elgin, C. and Goodman, N., 'Interpretation and Identity', Critical Inquiry 12, (1986), 562-575.

Haapala,A, What is a Work of Literature?, (Acta Philosophica Fennica; 46. Helsinki 1989) 
Hirsch, E.D., Validity in Interpretation, Yale, University Press, New Haven, Conn., 1967.

Julh, P.D.,Interpretation, Princeton University Press, Princeton, 1980.

Kjørup, S., 'Pictorial Speech Acts', Erkenntnis 12 (1978), 55-71.

Margolis, J., Art and Philosophy, Harvester Press, Sussex, 1980.

Pratt, M.L., Toward a Speech Act Theory of Literary Discourse, Indiana University Press, Bloomington, 1977.

Rantala, V., 'The Work of Art: Identity and Interpretation; Semiotica 76 (1990)

Rosenthal, D.M., 'Intentionality,' Midwest Stud ies in Philosophy X (1986), 151-184.

Searle, J., Intentionality, Cambridge University Press, Cambridge, 1983.

Wimsatt, W.K. and Beardsley, M.C., 'The Intentional Fallacy', in W.K. Wimsatt, The Verbal Icon. Studies in the Meaning of Poetry, University of Kentucky Press, Lexington, 1954, pp. 3-18. 
